\title{
Detection of circulating natural antibodies to inflammatory cytokines in type-2 diabetes and clinical significance
}

\author{
Weiyi Cai ${ }^{1 \dagger}$, Cailing Qiu ${ }^{2 \dagger}$, Hongyu Zhang ${ }^{3}$, Xiangyun Chen ${ }^{2}$, Xuan Zhang ${ }^{3}$, Qingyong Meng ${ }^{1 *}$ and Jun Wei ${ }^{4 *}$
}

\begin{abstract}
Background: Inflammatory cytokines have been demonstrated to be involved in developing insulin resistance and type-2 diabetes (T2D). Natural antibodies in the circulation have protective effects on common diseases in humans. The present study was thus designed to test the hypothesis that natural antibodies against inflammatory cytokines could be associated with T2D.
\end{abstract}

Methods: An enzyme-linked immunosorbent assay (ELISA) was developed in-house to detect plasma IgG against peptide antigens derived from interleukin 1a (IL1a), IL1 $\beta$, IL6, IL8 and tumor necrosis factor-a (TNF-a) in 200 patients with T2D and 220 control subjects.

Results: Binary regression showed that compared with control subjects, T2D patients had a decreased level of plasma anti-IL6 lgG (adjusted $r^{2}=0.034, p=0.0001$ ), anti-IL8 IgG (adjusted $r^{2}=0.021, p=0.002$ ) and anti-TNF-a lgG (adjusted $r^{2}=0.017, p=0.003$ ). Female patients mainly contributed to decreased levels of anti-IL6 IgG (adjusted $r^{2}=0$. 065, $p=0.0008$ ) and anti-IL8 IgG (adjusted $r^{2}=0.056, p=0.003$ ), while male patients mainly contributed to decreased anti-TNF-a lgG levels (adjusted $r^{2}=0.024, p=0.005$ ). ROC curve analysis revealed a sensitivity of $16.5 \%$ against specificity of $95.5 \%$ for anti-IL 6 lgG assay and a sensitivity of 19.5\% against specificity of 95.9\% for anti-IL8 IgG assay. Glycated hemoglobin levels measured after 6-month glucose-lowering treatment appeared to be inversely correlated with plasma anti-IL1a IgG $(r=-0.477, \mathrm{df}=17, p=0.039)$ and anti-IL6 IgG $(r=-0.519, \mathrm{df}=17, p=0.023)$ although such correlation failed to survive the Bonferroni correction.

Conclusions: Deficiency of natural lgG against inflammatory cytokines is likely to be a risk factor for T2D development and detection of such antibodies may be useful for personalized treatment of the disease.

Keywords: Natural antibodies, IgG antibody, Inflammatory cytokines, Type-2 diabetes, ELISA

\section{Background}

Type-2 diabetes (T2D) is a metabolic disorder that results from interaction between genetic predisposition and environmental components [1]. The prevalence of T2D is rising globally, accounting for $85 \%-95 \%$ of all forms of diabetes in developed countries and a higher percentage in developing countries [2]. China has become a global

\footnotetext{
*Correspondence: qingyong_meng@outlook.com; jun.wei@uhi.ac.uk ${ }^{\dagger}$ Equal contributors

${ }^{1}$ Laboratory for Nursing Science \& Institute of Laboratory Medicine, Guangdong Medical University, No.1 Xincheng Road, Dongguan 523808, China

${ }^{4}$ Division of Health Research, University of the Highlands \& Islands, Centre for Health Science, Perth Road, Inverness IV2 3JH, UK

Full list of author information is available at the end of the article
}

epicenter of diabetes; a national study from June 2007 through May 2008 demonstrated that the prevalence of diabetes was $9.7 \%$ among Chinese adults [3]. Obesity is a major risk factor for T2D and obesity-induced chronic inflammation is likely to play a key role in the pathogenesis of insulin resistance that leads to the development of T2D $[4,5]$. Multiple inflammatory inputs contribute to metabolic dysfunction [6]. The World Health Organization (WHO) published an epidemiological report in 2014, indicating that more than 1.9 billion adult people (18 years and older) in the world were overweight, 600 millions of whom were obese (http://www.who.int/mediacentre/fact sheets/fs311/en/index.html). It is worth noting that approximately one third of the population is overweight or 
obese, but only $\sim 5 \%$ develops T2D. There must be something in our body to regulate susceptibility to T2D in obese people.

Inflammatory cytokines, such as interleukin 1 (IL1), IL6 and tumor necrosis factor alpha (TNF- $\alpha$ ) have been confirmed to be involved in developing insulin resistance [7]. Circulating IL8 was also found to be elevated in patients with T2D and associated with obesity-related parameters $[8,9]$. Anti-inflammatory system could reduce susceptibility to insulin resistance and T2D. It has been indicated that the blockage of inflammatory cytokines has T2D-protective characteristics $[4,10]$. Monoclonal antibodies targeting inflammatory cytokines have been used to treat coronary artery disease [11], rheumatoid arthritis and other systemic autoimmune diseases $[12,13]$. Natural antibodies are defined as immunoglobulins that are spontaneously and constitutively secreted by the $\mathrm{B} 1$ type of lymphocytes in the absence of external antigen stimulation or immunization [14, 15]. Natural antibodies play an important role not only in eliminating pathogens invaded but also in maintaining homeostasis of the immune system by prevention of autoimmune and inflammatory reactions [16-19]. Possibly, the content of natural antibodies is in inverse proportion to inflammatory cytokines, and a decrease in natural antibody levels may lead to increased activities of inflammatory cytokines [20-22]. From an immunological point of view, the effects of inflammatory cytokines on our body may depend on circulating levels of their corresponding natural antibodies [15]. Accordingly, the present work was undertaken to examine if circulating levels of natural antibodies against inflammatory cytokines were associated with T2D and the therapeutic effects of glucose-lowering treatment on the disease in a Chinese population.

\section{Methods}

\section{Subjects}

A total of 200 patients aged $48.2 \pm 7.2$ years, who were diagnosed as having T2D, and 220 healthy controls aged $44.2 \pm 8.6$ years, were recruited by Dalang Hospital of Dongguan, China for this study. These 200 patients had a disease duration of $1.9 \pm 2.4$ years on average, ranging from 0 to 9.4 years and they all fulfilled the diagnostic criteria for diabetes published by the WHO, 2006. (http://www. who.int/diabetes/publications/diagnosis_diabetes2006/en/). Those patients who developed clinical complications or suffered from autoimmune disease, malignant disease and mental illness, were excluded from this study. Glycated hemoglobin (HbA1c) levels in blood were taken from clinical records if available, which were measured before glucose-lowering treatment and in 3 and 6 months of posttreatment. Control subjects did not have history of diabetes, autoimmune disease, malignant illness and mental disorders. There were 54 smokers $(27.0 \%)$ in the patient group and 60 smokers (27.3\%) in the control group. All the subjects were of Chinese Han origin, and all gave written informed consent to participate in this study. This work was approved by an Institutional Review Board and conformed to the requirements of the Declaration of Helsinki.

\section{Antibody testing}

Five linear peptide antigens that are respectively derived from IL1 $\alpha$, IL1ß, IL6, IL8 and TNF- $\alpha$, were designed according to the computational prediction of human leukocyte antigen (HLA) class II epitopes [23, 24], and their amino acid sequences are given in Table 1. An enzyme-linked immunosorbent assay (ELISA) was developed in-house based on a recent publication [25]. Briefly, solid-phase synthetic peptides were dissolved in $67 \%$ acetic acid to obtain a concentration of $5 \mathrm{mg} / \mathrm{ml}$ as stock solution. Maleimide-activated plates (Thermo Scientific, Shanghai, China) were coated according to the Manufacturer's instruction. The antigen-coated plates were washed twice with $200 \mu \mathrm{l}$ Wash Buffer that was phosphate-buffered saline (PBS) (P4417, Sigma-Aldrich, Shanghai, China) containing $0.05 \%$ Tween-20; 50 $\mu \mathrm{l}$ plasma sample diluted 1:200 in Assay Buffer that was PBS containing 0.5\% bovine serum albumin (BSA) was then added to each sample well; $50 \mu \mathrm{l}$ Assay Buffer was added to each negative control (NC) well and $50 \mu$ positive control (PC) sample was added to each $\mathrm{PC}$ well. Following incubation at room temperature for 1.5 hours, the plate was washed three times with $200 \mu \mathrm{l}$ Wash Buffer and $50 \mu \mathrm{l}$ peroxidase-conjugated goat anti-human IgG antibody (ab98567, Abcam, Guangzhou, China) diluted 1:50000 in Assay Buffer was added to each well. After incubation at room temperature for 1 hour, color development was initiated by adding 50 $\mu$ l Stabilized Chromogen (SB02, Life Technologies, Guangzhou, China) and terminated after $20 \mathrm{~min}$ by adding $25 \mu \mathrm{l}$ Stop Solution (SS04, Life Technologies). The measurement of optical density (OD) was completed on a microplate reader within 10 min at $450 \mathrm{~nm}$ with a reference wavelength of $620 \mathrm{~nm}$. All the samples were tested in duplicate and the specific binding ratio (SBR) was used to represent the relative levels of plasma IgG antibodies. Calculation of SBR is as follows: $\mathrm{SBR}=\left(\mathrm{OD}_{\text {Sample }}-\mathrm{OD}_{\mathrm{NC}}\right) /\left(\mathrm{OD}_{\mathrm{PC}}-\mathrm{OD}_{\mathrm{NC}}\right)$

To minimize an intra-assay deviation, the ratio of the difference between duplicated OD values of each sample to their sum was used to assess the precision for the in-

Table 1 Sequence of peptide antigens used for in-house ELISA

\begin{tabular}{ll}
\hline Antigen & Sequence \\
\hline IL1a & LLFFWETHGTKNYFTSVAHPNLFIATKQDYWVCLAGGP \\
IL1 $\beta$ & LNCTLRDSQQKSLVMSGPYELKALHLQGQDMEQQWF \\
IL6 & TCLVKIITGLL EFEVYLEYLQNRFESSEEQARAVQM \\
IL8 & ELRCQCIKTYSKPFHPKFIKELRVIESGPH \\
TNF-a & LIYSQVLFKGQGCPSTHVLLTHTISRIAVSYQTKVNLLS \\
\hline
\end{tabular}


house ELISA antibody test. If the ratio was found to be $>10 \%$, the test of this sample was treated as being invalid and was not used for data analysis.

\section{Data analysis}

The coefficient of variation $(\mathrm{CV})$ was used to represent an inter-assay deviation estimated using pooled plasma, namely quality control (QC) sample, which was randomly collected from $>20$ healthy subjects and tested on every 96-well plate. Binary regression analysis was applied to examine the differences in circulating IgG levels between T2D patients and control subjects, with adjustment for age in either male or female samples, and for gender and age in combined samples. Pearson correlation analysis was performed to examine the correlation between plasma IgG levels and the duration of T2D or HbA1c levels in blood. Receiver operating characteristic (ROC) curve analysis was applied to estimate the areas under the ROC curve (AUC) with calculation of ELISA sensitivity against a specificity of $\geq 95 \%$ as well as $95 \%$ confident interval (CI). Because five antigens were tested in this study, the p-value of 0.01 was considered to be statistically significant based on the Bonferroni correction.

\section{Results}

The CV estimated based on SBR from the QC sample was $16.2 \%$ for anti-IL1 $\alpha$ IgG assay, $9.5 \%$ for anti-IL1 $\beta$ IgG assay, $8.6 \%$ for anti-IL6 IgG assay, $13.9 \%$ for antiIL8 IgG assay and $11.7 \%$ for anti-TNF- $\alpha$ IgG assay (Table 2), suggesting that the in-house ELISA developed with linear peptide antigens was highly reproducible.

Binary regression analysis showed that compared with control subjects, T2D patients had a decreased level of circulating IgG against peptide antigens derived from IL6 (adjusted $r^{2}=0.034, p=0.0001$ ), IL8 (adjusted $r^{2}=0.021$, $p=0.002$ ) and TNF- $\alpha$ (adjusted $r^{2}=0.017, p=0.003$ ). Female patients mainly contributed to decreased levels of anti-IL6 IgG (adjusted $r^{2}=0.065, p=0.0008$ ) and IL8 IgG (adjusted $r^{2}=0.056, p=0.003$ ), while male patients mainly contributed to decreased anti-TNF- $\alpha$ IgG levels (adjusted $\left.r^{2}=0.024, p=0.005\right)$. Circulating IgG against peptide antigens derived from IL1 $\alpha$ and IL1 $\beta$ did not show a significant change in patients with T2D (Table 3).

Table 2 Inter-assay deviation between ELISA-testing plates

\begin{tabular}{llll}
\hline Antigen & Number of plates & Mean \pm SD $^{\text {a }}$ & CV (\%) \\
\hline IL1a & 20 & $1.70 \pm 0.28$ & 16.2 \\
IL1 $\beta$ & 23 & $1.12+0.11$ & 9.5 \\
IL6 & 20 & $1.38+0.12$ & 8.6 \\
IL8 & 20 & $1.41+0.17$ & 11.7 \\
TNF- $a$ & 23 & $1.33+0.19$ & 13.9 \\
\hline
\end{tabular}

${ }^{\mathrm{a}} \mathrm{SD}$ standard deviation
Table 3 Binary regression analysis of circulating lgG against inflammatory cytokines in T2D

\begin{tabular}{|c|c|c|c|c|}
\hline Antigens & Patient $(n)$ & Control $(n)$ & Adjusted $r^{2}$ & $p^{a}$ \\
\hline \multicolumn{5}{|l|}{ IL1a } \\
\hline Male & $1.15 \pm 0.42(124)$ & $1.21 \pm 0.39(131)$ & -0.002 & 0.228 \\
\hline Female & $1.20 \pm 0.43(76)$ & $1.32 \pm 0.39$ (89) & 0.009 & 0.083 \\
\hline Combined & $1.17 \pm 0.42(200)$ & $1.26 \pm 0.39(220)$ & 0.012 & 0.04 \\
\hline \multicolumn{5}{|l|}{ ILI $\beta$} \\
\hline Male & $0.70 \pm 0.28(124)$ & $0.77 \pm 0.30(131)$ & 0.019 & 0.04 \\
\hline Female & $0.78 \pm 0.31(76)$ & $0.80 \pm 0.33(89)$ & -0.01 & 0.788 \\
\hline Combined & $0.73 \pm 0.29(200)$ & $0.78 \pm 0.31(220)$ & 0.011 & 0.07 \\
\hline \multicolumn{5}{|l|}{ IL6 } \\
\hline Male & $1.13 \pm 0.21(124)$ & $1.18 \pm 0.19(131)$ & 0.01 & 0.038 \\
\hline Female & $1.11 \pm 0.23(76)$ & $1.24 \pm 0.22(89)$ & 0.065 & 0.0008 \\
\hline Combined & $1.12 \pm 0.22(200)$ & $1.20 \pm 0.21(220)$ & 0.034 & 0.0001 \\
\hline \multicolumn{5}{|l|}{ IL8 } \\
\hline Male & $0.97 \pm 0.35(124)$ & $1.02 \pm 0.29(131)$ & 0.003 & 0.134 \\
\hline Female & $0.94 \pm 0.33(76)$ & $1.12 \pm 0.35$ (89) & 0.056 & 0.003 \\
\hline Combined & $0.96 \pm 0.34(200)$ & $1.06 \pm 0.32(220)$ & 0.021 & 0.002 \\
\hline \multicolumn{5}{|l|}{ TNF-a } \\
\hline Male & $0.77 \pm 0.40(124)$ & $0.95 \pm 0.60(131)$ & 0.024 & 0.005 \\
\hline Female & $0.85 \pm 0.48(76)$ & $0.95 \pm 0.45(89)$ & -0.002 & 0.226 \\
\hline Combined & $0.80 \pm 0.43(200)$ & $0.95 \pm 0.54(220)$ & 0.017 & 0.003 \\
\hline
\end{tabular}

Data were expressed as mean \pm SD. ${ }^{a}$ Adjusted for age in male and female samples, and for gender and age in combined samples.

As shown in Table 4, none of plasma IgG antibodies for these five inflammatory cytokines was significantly correlated with $\mathrm{HbA1c}$ levels measured either before glucoselowering treatments or after 3-month treatment. However, HbA1c levels measured after 6-month glucose-lowering treatment appeared to be inversely correlated with anti-I $\operatorname{IL} 1 \alpha \operatorname{IgG}(r=-0.477, \mathrm{df}=17, p=0.039)$ and anti-IL6 IgG $(r=-$ $0.519, \mathrm{df}=17, p=0.023)$, although such significant correlations failed to survive the Bonferroni correction $(p>0.01)$.

ROC curve analysis revealed that anti-IL6 IgG assay had an AUC of 0.601 (95\% CI 0.55-0.66) with sensitivity of $16.5 \%$ against a specificity of $95.5 \%$, and anti-IL8 IgG assay had an AUC of 0.593 (95\% CI 0.54-0.65) with

Table 4 Correlation between plasma IgG and $\mathrm{HbA1c}$ levels in T2D patients before and after glucose-lowering treatment

\begin{tabular}{|c|c|c|c|c|c|c|}
\hline \multirow[t]{2}{*}{ Antigen } & \multicolumn{2}{|c|}{ Before treatment } & \multicolumn{2}{|c|}{ 3-month treatment } & \multicolumn{2}{|c|}{ 6-month treatment } \\
\hline & $r$ & $\overline{p^{a}}$ & $r$ & $p^{\mathrm{b}}$ & $r$ & $p^{c}$ \\
\hline IL1a & -0.024 & 0.762 & -0.005 & 0.978 & -0.477 & 0.039 \\
\hline IL1 $\beta$ & -0.011 & 0.888 & -0.030 & 0.875 & -0.278 & 0.250 \\
\hline IL6 & -0.052 & 0.517 & -0.191 & 0.304 & -0.519 & 0.023 \\
\hline IL8 & -0.089 & 0.266 & -0.239 & 0.196 & -0.400 & 0.090 \\
\hline TNF-a & 0.069 & 0.384 & -0.129 & 0.489 & -0.137 & 0.576 \\
\hline
\end{tabular}

${ }^{a} d f=157 ;{ }^{b} d f=29 ;{ }^{c} d f=17$ 


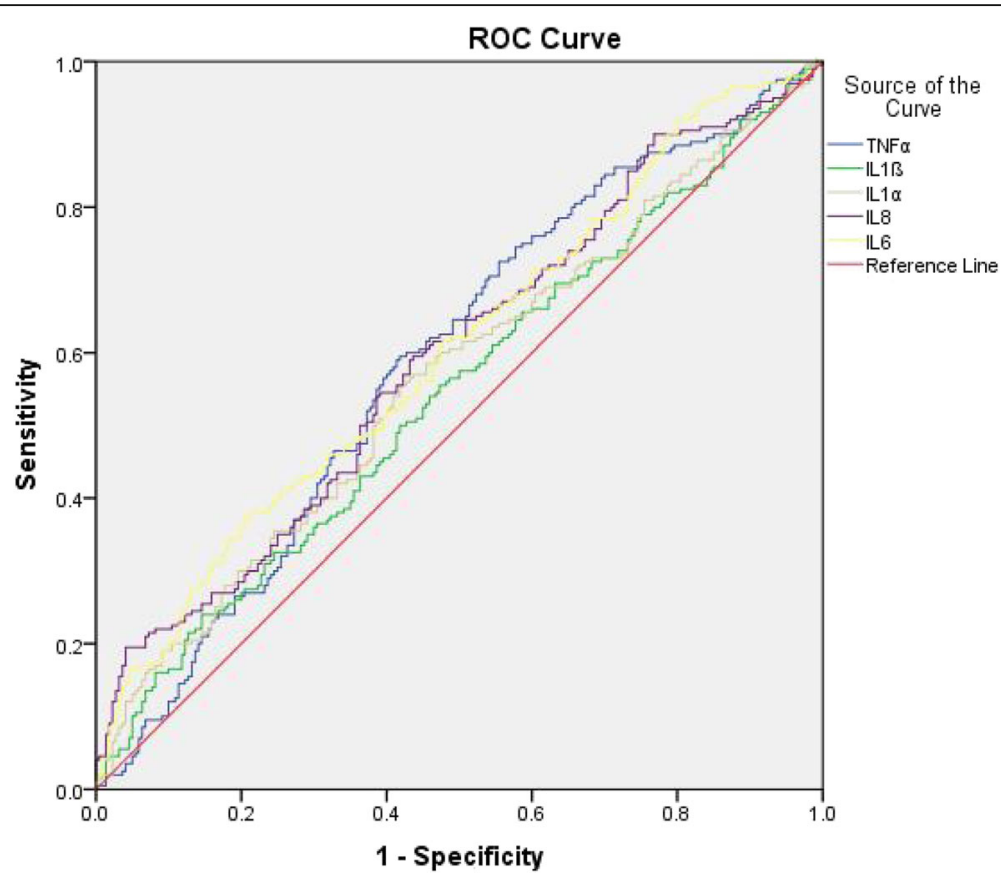

Fig. 1 ROC curve analysis of circulating IgG against inflammatory cytokines in T2D. Anti-IL1a lgG had an AUC of 0.564 (95\% Cl 0.509-0.619) with sensitivity of $13.0 \%$ against a specificity of $95.0 \%$; anti-IL $1 \beta$ lgG had an AUC of 0.544 ( $95 \%$ Cl $0.489-0.599)$ with sensitivity of $10.0 \%$ against a specificity of 95.0\%; anti-lL6 lgG had an AUC of 0.601 ( 95\% Cl 0.547-0.655) with sensitivity of 16.5\% against a specificity of 95.5\%; anti-IL8 lgG had an AUC of 0.593 $(95 \% \mathrm{Cl} 0.538-0.647)$ with sensitivity of $19.5 \%$ against a specificity of $95.9 \%$; anti-TNF-a lgG had an AUC of 0.589 (95\%Cl $0.534-0.643)$ with sensitivity of $4.5 \%$ against a specificity of $95.0 \%$
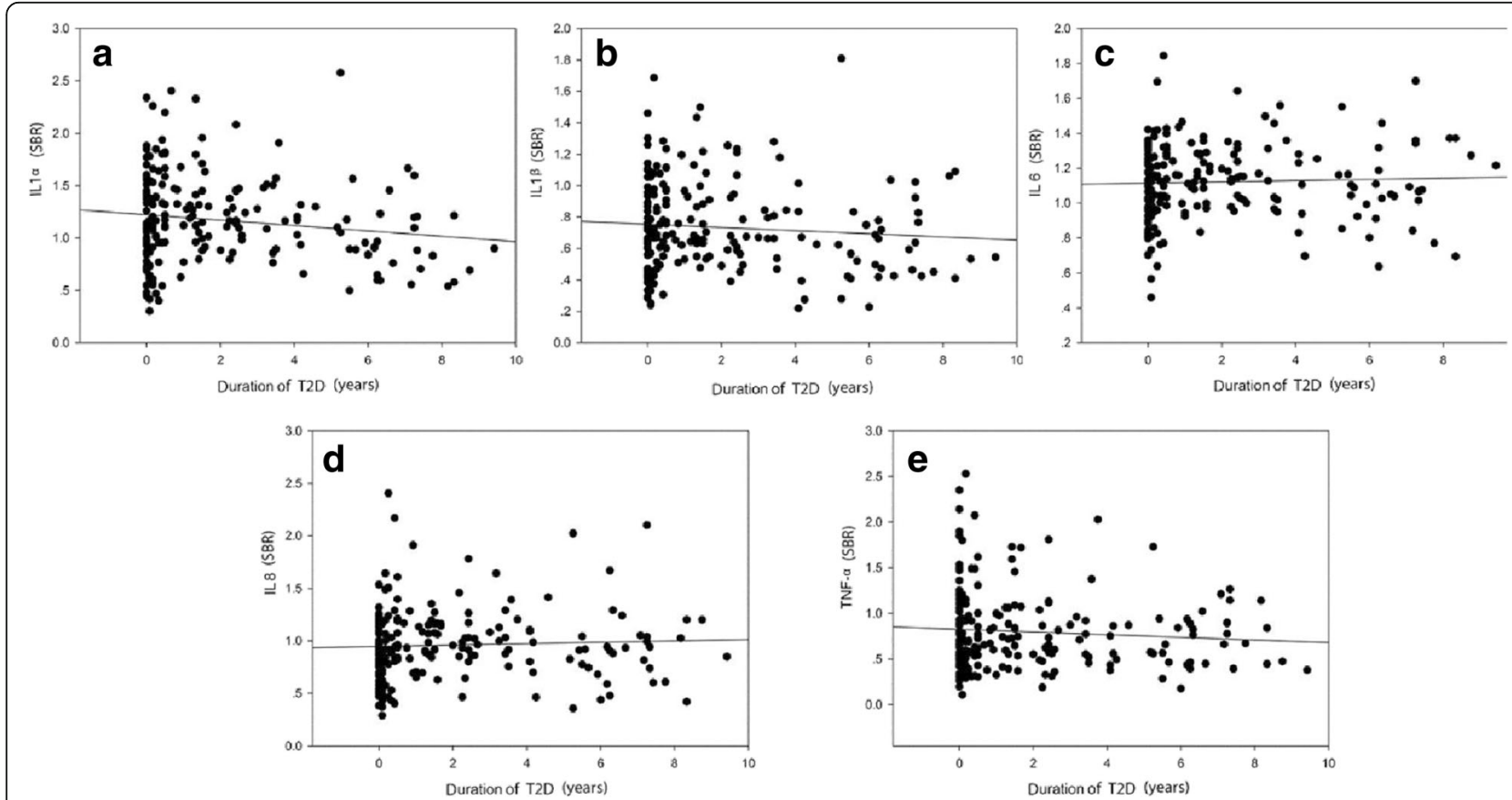

Fig. 2 Correlation between the duration of T2D and the levels of circulating $\lg G$ against inflammatory cytokines $\mathbf{a}$. IL $1 \mathrm{a} \lg G: r=-0.148, \mathrm{df}=199$, $p=0.037 ; \mathbf{b}$. IL $1 \beta \mathrm{lgG}: r=-0.085, \mathrm{df}=199, p=0.234 ; \mathbf{c}$. IL6 IgG: $r=0.04, \mathrm{df}=199, p=0.576 ; \mathbf{d}$. IL8 IgG: $r=0.047, \mathrm{df}=199, p=0.508 ; e$. TNF-a lgG: $r=-0.083, d f=199, p=0.242$ 
sensitivity of $19.5 \%$ against a specificity of $95.9 \%$; all other three IgG tests had a sensitivity of less than $15 \%$ against the specificity of $95 \%$ (Fig. 1). Pearson correlation analysis failed to show a significant correlation between the duration of T2D and the levels of circulating $\operatorname{IgG}$ against inflammatory cytokines (Fig. 2).

\section{Discussion}

Natural antibodies are present in both animals and humans; they are thought to comprise the bulk of resting IgM, along with portions of isotype-switched IgA and IgG [26, 27]. Natural antibodies also tend to be autoreactive and perform a second beneficial function in housekeeping and homeostatic activity for elimination of dying cells and noxious molecular species [16, 28]. It is believed that natural antibodies are related to the most common, distressing and burdensome diseases, majority of which is associated with aging [15]. In this study, we found that deficiency of natural antibodies against IL6, IL8 and TNF- $\alpha$ was associated with T2D (Table 3) although their levels in the circulation may not be correlated with the duration of T2D (Fig. 2). ROC curve analysis revealed a sensitivity of $>15 \%$ against the specificity of $>95 \%$ for both the anti-IL6 assay and the anti-IL8 IgG assay. The sensitivity may represent a clinical subgroup that has undergone an inflammatory process in patients with T2D. Interestingly, HbA1c levels in blood are inversely correlated with plasma anti-IL1 $\alpha$ and antiIL6 IgG levels (Table 4). These observations raise the possibility that natural antibodies against inflammatory cytokines may be useful biomarkers for the development of personalized treatment of T2D on the one hand, and on the other hand, they can also serve as a key component in the body to bridge the gap between T2D and obesity, and counteract the onset of obesity-related diseases.

Gender differences in insulin resistance and T2D have been observed in several studies [29-32]. Women with T2D generally have poor glycemic control and are less likely to reach the goals for HbA1c, as compared with men [30]. Diversities in biology, culture, lifestyle, environment and socioeconomic status impact the differences in risk, pathophysiology and complications of T2D between male and female patients [32]. In this study, we found that there was a gender difference in circulating IgG antibodies against inflammatory cytokines (Table 3); decreased levels of anti-IL6 and anti-IL8 IgG antibodies were more likely to occur in female than male patients, whereas deficiency of anti-TNF- $\alpha$ IgG was more likely to be observed in male than female patients. The gender differences in natural IgG antibodies against inflammatory cytokines provide a clue to the insight into the pathological mechanism behind T2D development in humans. To our knowledge, this is the first report on a decrease in circulating IgG antibodies against inflammatory cytokines. However, this is a piece of preliminary work and the initial finding needs further replication in a large sample size and also in subpopulations.

\section{Conclusions}

Deficiency of natural IgG against inflammatory cytokines is likely to be a risk factor for T2D development and detection of such antibodies may be useful for personalized treatment of the disease.

\section{Additional file}

Additional file 1: Supplementary information. (XLSX $195 \mathrm{~kb}$ )

\section{Abbreviations}

AUC: Areas under the ROC curve; BSA: Bovine serum albumin; $\mathrm{Cl}$ : Confident interval; CV: Coefficients of Variation; ELISA: Enzyme-linked immunosorbent assay; HbA1c: Glycated hemoglobin; HLA: Human leukocyte antigen; IgA: Immunoglobulin A; IgG: Immunoglobulin G; IgM: Immunoglobulin $M_{\text {; }}$ IL1a: Interleukin 1a; IL1 $\beta$ : Interleukin 1 $;$; IL6: Interleukin 16; IL8: Interleukin 8; NC: Negative control; OD: Optical density; PBS: Phosphate -buffered saline; PC: Positive control; QC: Quality control; ROC: Receiver operating characteristic curve; SBR: Specific binding ratio; T2D: Type-2 diabetes; TNFa: Tumor necrosis factor-a; WHO: World Health Organization

\section{Acknowledgements}

We thank all the patients and control subjects for their participation in this study.

Funding

This work was supported by Hailanshen Biomedical Technology Ltd, Shenzhen, China.

Availability of data and materials

A spreadsheet with detailed data is available as Additional file 1.

\section{Authors' contributions}

CW and QC mainly carried out laboratory work and data analysi; ZH, CX and ZX identified patients with diabetes and collected clinical data; MQ and WJ conceived of this study, supervised laboratory work and drafted manuscript. All authors read and approved the final manuscript.

Ethics approval and consent to participate

This work was approved by the Institutional Review Board of the Second Hospital of Jilin University, Changchun, China, (IRB\#: SHJU2017-101), and performed in accordance with the ethical standards as laid down in the 1964 Declaration of Helsinki and its later amendments.

Consent for publication

Not applicable.

Competing interests

All authors declared that they have no competing interests.

\section{Publisher's Note}

Springer Nature remains neutral with regard to jurisdictional claims in published maps and institutional affiliations.

\section{Author details}

${ }^{1}$ Laboratory for Nursing Science \& Institute of Laboratory Medicine, Guangdong Medical University, No.1 Xincheng Road, Dongguan 523808, China. ${ }^{2}$ Dalang Hospital of Dongguan, Dongguan 523000, China. ${ }^{3}$ The Second Hospital, Jilin University, Changchun 130041, China. ${ }^{4}$ Division of Health Research, University of the Highlands \& Islands, Centre for Health Science, Perth Road, Inverness IV2 3JH, UK. 
Received: 26 July 2017 Accepted: 28 October 2017

Published online: 06 November 2017

\section{References}

1. Stumvoll M, Goldstein BJ, van Haeften TW. Type 2 diabetes: Principles of pathogenesis and therapy. Lancet. 2005;365:1333-46.

2. Ramachandran A, Ma RC, Snehalatha C. Diabetes in Asia. Lancet. 2010;375: 408-18.

3. Yang W, Lu J, Weng J, Jia W, Ji L, Shan Z, Ji L, Xiao J, Shan Z, Liu J, Tian H, Ji Q, Zhu D, Ge J, Lin L, Chen L, Guo X, Zhao Z, Li Q, Zhou Z, Shan G, He J. China National Diabetes and Metabolic Disorders Study Group: Prevalence of diabetes among men and women in China. N Engl J Med. 2010;362:1090-101.

4. de Luca C, Olefsky JM. Inflammation and insulin resistance. FEBS Lett. 2008; 582:97-105.

5. Mushtaq G, Khan JA, Kumosani TA, Kamal MA. Alzheimer's disease and type 2 diabetes via chronic inflammatory mechanisms. Saudi J Biol Sci. 2015;22:4-13.

6. Lumeng CN, Saltiel AR. Inflammatory links between obesity and metabolic disease. J Clin Invest. 2011;121:2111-7.

7. Bastard JP, Maachi M, Lagathu C, Kim MJ, Caron M, Vidal H, Capeau J, Feve B. Recent advances in the relationship between obesity, inflammation, and insulin resistance. Eur Cytokine Netw. 2006;17:4-12.

8. Abou-Shousha S, Abd El-Megeed MH, Sultan HK. Interleukin-8, ferritin and soluble transferrin receptors in type II diabetes mellitus. Egypt J Immunol. 2006;13:19-25.

9. Kim CS, Park HS, Kawada T, Kim JH, Lim D, Hubbard NE, Kwon BS, Erickson $\mathrm{KL}$, Yu R. Circulating levels of MCP-1 and IL-8 are elevated in human obese subjects and associated with obesity-related parameters. Int J Obes (Lond). 2006:30:1347-55

10. Herder C, Carstensen M. OuwensDM: Anti-inflammatory cytokines and risk of type 2 diabetes. Diabetes Obes Metab. 2013;15(suppl 3):39-50.

11. Ridker PM, Everett BM, Thuren T, MacFadyen JG, Chang WH, Ballantyne C, Fonseca F, Nicolau J, Koenig W, Anker SD, Kastelein JJP, Cornel JH, Pais P, Pella D, Genest J, Cifkova R, Lorenzatti A, Forster T, Kobalava Z, Vida-Simiti L, Flather M, Shimokawa H, Ogawa H, Dellborg M, Rossi PRF, Troquay RPT, Libby P, Glynn RJ, CANTOS Trial Group. Antiinflammatory Therapy with Canakinumab for Atherosclerotic Disease. N Engl J Med. 2017;377:1119-31.

12. Murdaca G, Spanò F, Puppo F. Long-term treatment of rheumatoid arthritis with adalimumab. Open Access Rheumatol. 2013;5:43-9.

13. Ogata A, Tanaka T. Tocilizumab for the treatment of rheumatoid arthritis and other systemic autoimmune diseases: current perspectives and future directions. Int J Rheumatol. 2012;2012:946048. doi:10.1155/2012/946048.

14. Schwartz-Albiez R, Monteriro RC, Rodriguez M, Binder CJ, Shoenfeld Y. Natural antibodies, intravenous immunoglobulin and their role in autoimmunity, cancer and inflammation. Clin Exp Immunol. 2009:158(Suppl 1):43-50.

15. Rothstein TL. Natural Antibodies as Rheostats for Susceptibility to Chronic Diseases in the Aged. Front Immunol. 2016;7:127.

16. Shaw PX, Hörkkö S, Chang MK, Curtiss LK, Palinski W, Silverman GJ, Witztum JL. Natural antibodies with the T15 idiotype may act in atherosclerosis, apoptotic clearance, and protective immunity. J Clin Invest. 2000;105:1731-40.

17. Silverman GJ. Protective natural autoantibodies to apoptotic cells: evidence of convergent selection of recurrent innate-like clones. Ann N Y Acad Sci. 2015;1362:164-75

18. Vincent $T$, Plawecki M, Goulabchand R, Guilpain P, Eliaou JF. Mergining clinical phenotypes associated with anti-cytokine autoantibodies. Autoimmun Rev. 2015;14:528-35.

19. Born WK, Huang Y, Zeng W, Torres RM, O'Brien RL. A Special Connection between $\gamma \delta T$ Cells and Natural Antibodies? Arch Immunol Ther Exp (Warsz). 2016;64:455-62.

20. Pasquier B, Launay P, Kanamaru Y, Moura IC, Pfirsch S, Ruffié C, Hénin D, Benhamou M, Pretolani M, Blank U, Monteiro RC. Identification of FcaRl as an inhibitory receptor that controls inflammation. Immunity. 2005;22:31-42.

21. Tsimikas S, Brilakis ES, Lennon RJ, Miller ER, Witztum JL, McConnell JP, Kornman KS, Berger PB. Relationship of lgG and lgM autoantibodies to oxidized low density lipoprotein with coronary artery disease and cardiovascular events. J Lipid Res. 2007:48:425-33.

22. Soto $Y$, Conde $H$, Aroche $R$, Brito $V$, Luaces $P$, Nasiff A, Obregón A, Vázquez López AM. Autoantibodies to oxidized low density lipoprotein in relation with coronary artery disease. Hum Antibodies. 2009:18:109-17.

23. Söllner J, Heinzel A, Summer G, Fechete R, Stipkovits L, Szathmary S, Mayer B. Concept and application of a computational vaccinology workflow. Immunome Res. 2010;6(suppl 2):S7.
24. Wang P, Sidney J, Kim Y, Sette A, Lund O, Nielsen M, Peters B. Peptide binding predictions for HLA DR, DP and DQ molecules. BMC Bioinformatics. 2010;11:568

25. Hallford P, Clair DS, Halley L, Mustard C, Wei J. A study of type-1 diabetes associated autoantibodies in schizophrenia. Schizophr Res. 2016;176:186-90.

26. Panda S, Ding JL. Natural antibodies bridge innate and adaptive immunity. J Immunol. 2015:194:13-20.

27. Montecino-Rodriguez $\mathrm{E}$, Leathers $\mathrm{H}$, Dorshkind K. Identification of a B-1 B cell-specified progenitor. Nat Immunol. 2006;7:293-301.

28. Rothstein TL, Griffin DO, Holodick NE, Quach TD, Kaku H. Human B-1 cells take the stage. Ann N Y Acad Sci. 2013:1285:97-114.

29. Kautzky-Willer A, Handisurya A. Metabolic diseases and associated complications: sex and gender matter. Eur J Clin Invest. 2009:39:631-48,

30. Arnetz $L$, Ekberg NR, Alvarsson M. Sex differences in type 2 diabetes: focus on disease course and outcomes. Diabetes Metab Syndr Obes. 2014;7:409-20.

31. Goedecke JH, George C, Veras K, Peer N, Lombard C, Victor H, Steyn K, Levitt NS. Sex differences in insulin sensitivity and insulin response with increasing agein black South African men and women. Diabetes Res Clin Pract. 2016;122:207-14.

32. Kautzky-Willer A, Harreiter J, Pacini G. Sex and Gender Differences in Risk, Pathophysiology and Complications of Type 2 Diabetes Mellitus. Endocr Rev. 2016:37:278-316.

\section{Submit your next manuscript to BioMed Central and we will help you at every step:}

- We accept pre-submission inquiries

- Our selector tool helps you to find the most relevant journal

- We provide round the clock customer support

- Convenient online submission

- Thorough peer review

- Inclusion in PubMed and all major indexing services

- Maximum visibility for your research

Submit your manuscript at www.biomedcentral.com/submit
) Biomed Central 